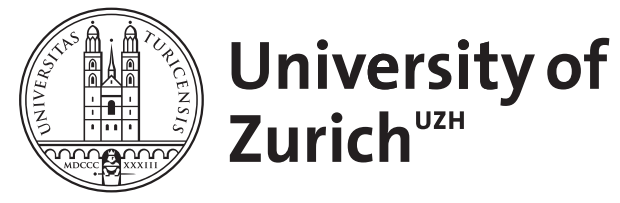
Archive

University of Zurich

University Library

Strickhofstrasse 39

CH-8057 Zurich

www.zora.uzh.ch

Year: 2017

\title{
Allergic skin diseases
}

Ong, Peck Y ; Schmid-Grendelmeier, Peter

DOI: https://doi.org/10.1016/j.iac.2016.10.001

Posted at the Zurich Open Repository and Archive, University of Zurich

ZORA URL: https://doi.org/10.5167/uzh-140849

Journal Article

Accepted Version

\section{(1) $(1) \Theta$}

The following work is licensed under a Creative Commons: Attribution-NonCommercial-NoDerivatives 4.0 International (CC BY-NC-ND 4.0) License.

Originally published at:

Ong, Peck Y; Schmid-Grendelmeier, Peter (2017). Allergic skin diseases. Immunology and Allergy Clinics of North America, 37(1):xv-xvi.

DOI: https://doi.org/10.1016/j.iac.2016.10.001 


\section{Preface}

\section{Allergic Skin Diseases}

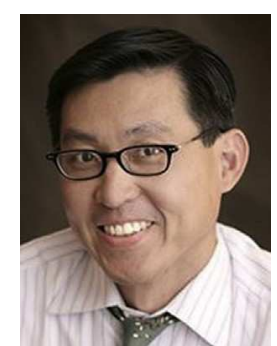

Peck Y. Ong, MD

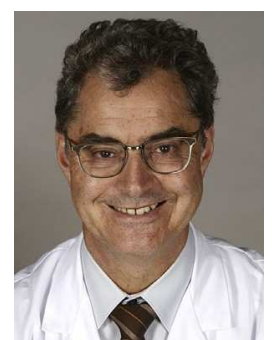

Peter Schmid-Grendelmeier, MD Editors

The current issue on Allergic Skin Diseases aims to provide a collection of practical tools for clinicians in their management of common allergic skin diseases, such as atopic dermatitis and urticaria. These tools include differential diagnosis, measurement of severity, evaluation of triggers, and treatments for severe cases and complications. Drs Gaudinski and Milner provided their insight on the pathogenesis and differential diagnosis of atopic dermatitis and urticaria based on a monogenetic approach of primary immunodeficiency conditions. A practical pictorial guide for the differential diagnosis of atopic dermatitis was delivered by Drs Barrett and Luu. Dr Weller and colleagues and Drs Thijs, de Bruin-Weller, and Hijnen contributed with updated reviews on the clinical measures and biomarkers for chronic urticaria and atopic dermatitis, respectively. Infectious triggers and complications of atopic dermatitis were discussed by Drs Glatz, Bosshard, and Schmid-Grendelmeier, and Drs Sun and Ong. Drs Bulkhi, Cooke, and Casale summarized the use of biologics in chronic urticaria, whereas Dr Kido-Nakahara and colleagues and Drs Nicol and Boguniewicz provided a concise review of potential anti-itch medications and a practical guide on wet wrap therapy for atopic dermatitis, respectively. In addition, this issue includes other allergic skin diseases and related conditions that are commonly encountered by primary physicians and allergists, including allergic contact dermatitis (Dr Kostner and colleagues), mastocytosis (Drs Schuch and Brockow), drug allergy (Drs Zalewska-Janowska, Spiewak, and Kowalski), angioedema (Drs Bas and Dreyfus), and food allergy (Dr Tam). These authors share their perspectives from Europe and 
the United States on each topic. We hope that this issue will add to the clinicians' armamentarium in their day-to-day management of these diseases.

Peck Y.Ong, MD

Division of Clinical Immunology and Allergy

Children's Hospital Los Angeles

Department of Pediatrics

University of Southern California

Keck School of Medicine

4650 Sunset Boulevard, MS 75

Los Angeles, CA 90027, USA

Peter Schmid-Grendelmeier, MD Allergy Unit, Department of Dermatology

University Hospital of Zurich

Christine-Kü hne Center for Allergy Research and Education (CK-CARE)

Gloriastrasse 31

8091 Zurich, Switzerland

E-mail addresses:

pyong@chla.usc.edu (P.Y. Ong)

peter.schmid@usz.ch (P. Schmid-Grendelmeier) 